\title{
Distribution of intertidal macrobenthic assemblages in relation to environmental factors in the Tagus estuary, western Portugal
}

\author{
ANXO CONDE ${ }^{1,2}$, JÚLIO M. NOVAIS ${ }^{1}$ and JORGE DOMÍNGUEZ ${ }^{2}$ \\ ${ }^{1}$ IBB-Institute for Biotechnology and Bioengineering, Centre for Biological and Chemical Engineering, \\ Instituto Superior Técnico (IST), 1049-001, Lisbon, Portugal. E-mail: aconde@uvigo.es \\ ${ }^{2}$ Departamento de Ecoloxía e Bioloxía Animal, Universidade de Vigo, Vigo E-36310, Spain.
}

\begin{abstract}
SUMMARY: Fourteen intertidal sites from the eastern mid-region of the Tagus estuary were considered in order to study their macrobenthic assemblages in relation to environmental factors. The salinity gradient was displayed in an ordination of the assemblages by non-metric multidimensional scaling (NMDS). However, salinity was not found to be a significant environmental factor to explain the distribution of the assemblages. Conversely, a lateral gradient characterized three clusters of sites identified in relation to their outer, intermediate and inner location also related to organic matter content, oxygen concentration and redox potential values. Although the hydrodynamic factor was not investigated it is thought to be an important environmental factor for characterizing the lateral gradient. As a general trend, there was a transition between the groups of assemblages from the lower estuary towards the inner and upstream locations. The polychaetes Lanice conchilega and Hediste diversicolor and the gastropod Hydrobia ulvae were the characteristic species in the outer, inner and intermediate groups of sites, respectively. It was concluded that the lateral gradient is the main environmental driver that explains the distribution of the intertidal macrobenthic assemblages in the Tagus estuary when the salinity gradient is not find to be a significant environmental factor.
\end{abstract}

Keywords: community transition, salinity gradient, lateral gradient, static factors, indicative species, estuarine zones.

RESUMEN: Distribución INTERMAREAL DE LAS POBLACIONES DE MACROINVERTEBRAdOS EN EL ESTUARIO DEL TAJO, PoRTugAl, EN RELACIÓN CON FACTORES AMBIENTALES. - Se han estudiado las poblaciones de macroinvertebrados y su distribución en relación a varios factores ambientales en catorce estaciones de muestreo da la zona intermareal situadas en la región central, margen Este, del estuario del Río Tajo. El gradiente salino fue sobrepuesto sobre las poblaciones macrobentónicas tras aplicar un escalado multidimensional no métrico (NMDS). El análisis reveló que la salinidad no es un factor ambiental significativo en la distribución de las poblaciones macrobentónicas de la zona en estudio. En cambio, se identificó un gradiente lateral que caracterizó los grupos de estaciones de muestreo agrupadas según su localización exterior, interior e intermedia, igualmente relacionadas con los factores ambientales contenido de materia orgánica, concentración de oxígeno y potencial redox. Aunque no se ha medido el factor hidrodinámico, éste parece ser importante para la definición del gradiente lateral. De modo general se observó una transición gradual entre los grupos de poblaciones macrobentónicas desde los situados en la parte de mayor influencia marina hacia aquellos que se distribuyeron en zonas más alejadas del mar en sentido lateral o longitudinal. Los poliquetos Lanice conchilega y Hediste diversicolor y el gasterópodo Hydrobia ulvae fueron las especies características de los grupos de estaciones exterior, interior e intermedio respectivamente. Se ha concluido que el gradiente lateral es el principal condicionante ambiental que explica la distribución de las poblaciones de macroinvertebrados intermareales en el estuario del Río Tajo cuando el gradiente salino no es significativamente importante.

Palabras clave: transición de poblaciones, gradiente salino, gradiente lateral, factores estáticos, especies indicadoras, regiones estuarinas.

\section{INTRODUCTION}

Estuaries are natural boundaries between marine and terrestrial systems and are considered among the most productive ecosystems (Nixon 1988). Estuaries are also characterized by a typical community that is well adapted to these transitional zones, which are usually subjected to anthropogenic pressure (Little 2000, 
McLusky and Elliott 2004).

Several types of habitats are found in estuaries (e.g. salt marshes, mudflats, sandflats, seagrass beds, oyster reefs and limnetic zones), and each type is inhabited by different assemblages that differ in terms of abundance and composition (Little 2000, Attrill and Rundle 2002). However, estuarine macroinvertebrate assemblages are quite similar along the European Atlantic coasts (Ysebaert et al. 1998, García-Arberas and Rallo 2002, Bocher et al. 2007). Moreover, estuaries have several features in common. For instance, salinity largely determines the distribution of macrobenthic assemblages in estuaries (Barnes 1989) along with depth (vertical gradient; Ysebaert et al. 1998, 2003) and sediment characteristics. Concordantly, coarser sediments are usually observed in the mouth of estuaries and finer sediments in inner regions (Elliot and McLusky 2002).

Some particular faunal features that may be highlighted for Atlantic Iberian estuaries are the absence of the bivalve Macoma balthica Linnaeus, 1758 (Jansen et al. 2007) and the occurrence of Corophium multisetosum Stock, 1952 (Queiroga 1990) or Corophium orientale Schellenberg, 1928, the latter in southern Portuguese coastal ecosystems (Gamito et al. 2010), rather than Corophium volutator (Pallas, 1766) in the upper reaches of estuaries. Salinity, sedimentary composition, organic matter content and current velocity have been described as structural environmental variables in Iberian estuaries (Moreira et al. 1993, Sousa et al. 2006, 2008), as in other European estuaries (Warwick et al. 1991, Ysebaert et al. 1998). The different types of habitat observed in estuaries are also conditioned by their position in relation to the extreme domains, freshwater and marine, that are found in these transitional waters (Attrill and Rundle 2002).

The present study attempts to find differences between intertidal macrobenthic assemblages in relation to environmental factors. Special attention is given to salinity, which is usually described as a main factor in structuring estuarine macrobenthic assemblages. Similarity between sites will allow different estuarine areas or habitat groups to be recognized. The approach may be useful for obtaining a broader perspective of the intertidal macroinvertebrate assemblages of the Tagus estuary previously studied in particular areas or habitats of this estuary (Rodrigues et al. 2006, Silva et al. 2006, França et al. 2009).

\section{MATERIALS AND METHODS}

\section{The study area}

The Tagus estuary is located in the centre of the Portuguese coast (Fig. 1) and is one of the largest estuaries in Europe (approximate length, $50 \mathrm{~km}$, and maximum width, $15 \mathrm{~km}$ ). It is a partially mixed mesotidal estuary with a tidal range varying from $1 \mathrm{~m}$ at neap tides to $4 \mathrm{~m}$ at spring tides. Most of the southern bank is dominated by intertidal mudflats and large salt

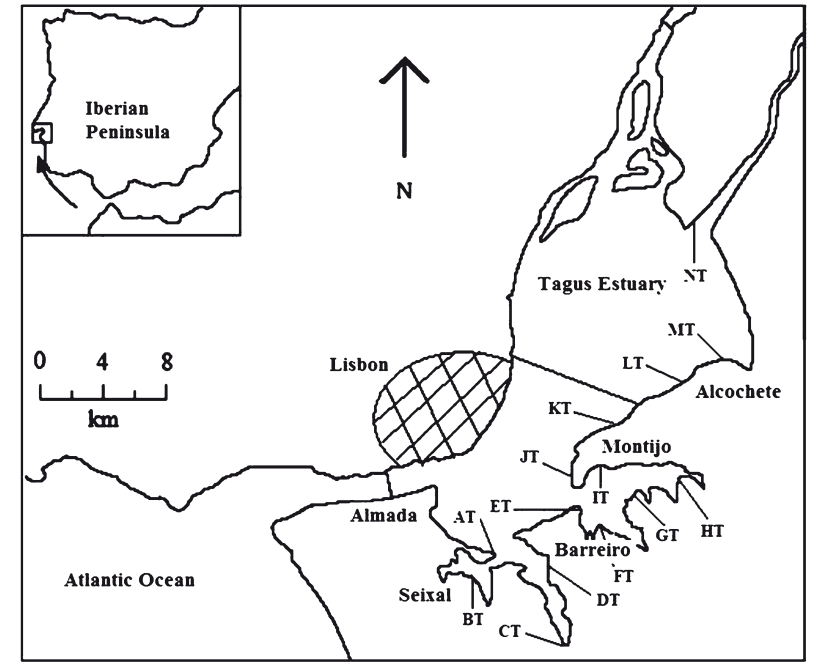

Fig. 1. - Map of the Tagus estuary showing the location of the sampling sites. Transversal lines between the estuary margins represent bridges.

marshes. An area of $c a .14560$ ha has been designated as a Nature Reserve and a larger area classified as a Special Protection Area for Birds, under the EEC Birds Directive.

The Nature Reserve does not provide easy access to the intertidal zone on the southern bank of the estuary. Moreover, extensive mudflats in the estuary, which represent approximately $40 \%$ of the area at low tide, act as physical barriers to carrying out easy sampling in many intertidal areas of the Tagus estuary. For instance, Rodrigues et al. (2006) and Silva et al. (2006) obtained grab samples from a boat during high tide to overcome difficulties associated with unconsolidated mudflat sediments. There are fewer salt marshes on the northern bank of the estuary, which has been greatly modified by human action and is much more urbanized and industrialized than the southern bank.

\section{Sampling and laboratory procedures}

Sampling was conducted on the southern bank of the estuary in summer, from 7 to 14 July 2009. Fourteen sites were sampled a priori without any particular criteria and designated by codes in alphabetical order from AT, BT, CT.... to NT (Fig. 1). The sampling survey was conducted from intertidal sites near the main axis of the estuary towards inner locations within the salt marshes and upper regions of the study site. The most distant sampling stations were separated by approximately $30 \mathrm{~km}$ in strait line.

Temperature, salinity, oxygen, redox potential and $\mathrm{pH}$ were measured in the interstitial water with a standard field probe (WTW 340i). The top $3 \mathrm{~cm}$ of the sediment were sampled to determine the sediment grain size by the dry sieving method. Sediment grainsize distribution was characterized as follows: gravel (>2 mm), coarse and medium sand $(2-0.250 \mathrm{~mm})$, fine sand $(0.250-0.063 \mathrm{~mm})$ and finest grains $(<0.063$ 
$\mathrm{mm}$ ), following Rodrigues et al. (2006) and Silva et al. (2006), although these authors considered coarse and medium sand content separately. Organic matter was determined by weight loss on ignition at $500^{\circ} \mathrm{C}$ for 24 $\mathrm{h}$ in a muffle furnace. Total organic nitrogen (TN) was measured in dry samples with an elemental analyzer (LECO CN2000).

Sampling for infaunal organisms was carried out with a corer with an inner diameter of $95 \mathrm{~mm}$ (7 replicates $=0.05 \mathrm{~m}^{2}$ ) inserted in the sediment to a depth of $30 \mathrm{~cm}$. All samples were sieved through a $1 \mathrm{~mm}$ mesh sieve (following Calvário 2001). The material retained was preserved in $70 \%$ ethanol. Benthic fauna was sorted under a dissecting microscope, counted and identified to the lowest possible taxonomic level. Species with abundance lower than $2 \%$ in all the sampling stations were excluded from the whole set of calculations. Biomass was assessed as blotted wet weight for all species. In addition ash-free dry weight (AFDW) was determined for bivalves by drying the organisms for $24 \mathrm{~h}$ at $105^{\circ} \mathrm{C}$ and ashing them at $550^{\circ} \mathrm{C}$ overnight.

\section{Data analysis and priori hypotheses}

The following ecological parameters were determined at each site: abundance, species richness, species diversity (H', Shannon-Weaver index, $\log _{2}$; Shannon and Weaver 1963) and evenness (J', Pielou's index; Pielou 1969). The results are shown as boxplots (Crawley 2007) or numerically as means and standard deviation $( \pm \mathrm{sd})$. The organisms were classified into five trophic groups in order to establish feeding guilds: suspension feeders (SF), deposit feeders (DF, including surface and sub-surface-deposit feeders), carnivores or predators $(\mathrm{P})$, omnivores $(\mathrm{O})$ and herbivores $(\mathrm{H})$. Functional groups were attributed in accordance with Gaudêncio and Cabral (2007), García-Arberas and Rallo (2002) and Ysebaert et al. (1998, 2003). The significance of the ecological parameters and the blotted wet weight biomass between sampling sites was tested by the Kruskal-Wallis test because normalization of the data was not possible. A posteriori pairwise comparisons were conducted by the use of the Wilcoxon signed-rank test. The Spearman rank correlation was also used to quantify the degree of correlation between fresh weight biomass and AFDW biomass of bivalves.

Non-metric multidimensional scaling (NMDS) was applied on the Hellinger transformed data with the goal of displaying salinity in relation to the distribution of the assemblages. The significance of salinity was tested by applying function "envfit" of the vegan package (Oksanen et al. 2006). Groups of minimum interpretable sites were formed by choosing an arbitrary threshold distance in cluster analysis (Clarke and Warwick 1994). Function ordisurf of the vegan package (Oksanen et al. 2006) was used to fit salinity contours to ordinations using generalized additive models (GAMs), which allow predictor variables to be modeled automatically by selection of the degree of smoothing through generalized cross-validation (Oksanen 2011). The sites were grouped spatially in accordance with the similarity of species composition (Legendre and Legendre 1998). The Hellinger transformation allows the Euclidean distance to be used in an NMDS while balancing the species abundance (Legendre and Gallagher 2001). Complete linkage agglomerative clustering was used because it is suitable for detecting discontinuities in the data (Borcard et al. 2011).

The indicator value index (IndVal; Dufrêne and Legendre 1997) was applied (package labdsv; see Borcard et al. (2011) for references) to identify the species that characterized the groups of sites by comparing the inter-species abundance and occurrence.

Non-parametric permutational multivariate analysis of variance (PERMANOVA) was applied to test for any changes in the macrobenthic assemblages caused by different species composition or abundance at different sites (Anderson 2001, Anderson 2005). The raw data for each replicate were subjected to Hellinger transformation prior to analysis. PERMANOVA also enables post-hoc analysis based on permutations that are uncorrected for multiple testing. The associated $\mathrm{p}$-value of the pairwise comparisons is provided as a Monte Carlo asymptotic p-value (Anderson 2005).

Principal components analysis (PCA) was applied in order to find different groups of sampling sites based on the abiotic variables, except temperature. Groups of minimum interpretable sites were formed by choosing an arbitrary threshold distance in cluster analysis of the standardized abiotic data set (mean $=0 ; s d=1)$ using the Euclidean distance (Clarke and Warwick 1994).

Canonical ordination was used to determine the spatial structure of the species assemblages in response to the environmental explanatory matrix. All the abiotic variables were used, with the exception of temperature, which is more appropriate for temporal gradients (McLusky 1993). Redundancy Analysis (RDA) was chosen because it enables transformation of the species data matrix (Legendre and Gallagher 2001, Borcard et al. 2011) by a method other than the chi-squared distance used in canonical correspondence analysis (Legendre and Gallagher 2001). RDA was applied to the correlation response matrix. RDA triplots were constructed using site scores based on the weighted sum of species (wa) as a counterbalance or midpoint between species composition and environmental constraints (following Oksanen 2011). Akaike's Information Criteria (AIC) was used to measure the goodness of fit of the RDA models (Oksanen 2011). Linear dependencies between environmental variables were assessed by computing Variance Inflation Factors (Oksanen et al. 2006), so that none of the variables surpassed a value of 10, as recommended by Borcard et al. (2011). The variance attributable to the first RDA axes was calculated with $\mathrm{R}_{\text {adj, }}^{2}$ which is usually low (Borcard et al. 2011). Permutation tests were used to assess the significance of the environmental variables and RDA axes of the constrained ordination and the environmental 
TABLE 1. - Mean values ( \pm sd) of the environmental variables measured at each sampling site.

\begin{tabular}{|c|c|c|c|c|c|c|c|c|}
\hline & Units & $\mathrm{AT}$ & BT & CT & DT & ET & FT & GT \\
\hline Sal & $\mathrm{psu}$ & $30.33 \pm 0.15$ & $20.37 \pm 0.06$ & $21.63 \pm 0.06$ & $30.80 \pm 0.00$ & $34.47 \pm 0.06$ & $32.97 \pm 0.06$ & $34.90 \pm 0.10$ \\
\hline $\mathrm{pH}$ & & $7.40 \pm 0.08$ & $7.21 \pm 0.02$ & $6.93 \pm 0.08$ & $6.93 \pm 0.04$ & $7.59 \pm 0.04$ & $7.91 \pm 0.08$ & $7.37 \pm 0.06$ \\
\hline$\left[\mathrm{O}_{2}\right]$ & $\mathrm{mg} / \mathrm{l}$ & $2.46 \pm 0.36$ & $0.14 \pm 0.00$ & $4.73 \pm 0.25$ & $4.28 \pm 0.48$ & $0.12 \pm 0.01$ & $6.85 \pm 0.37$ & $1.58 \pm 0.03$ \\
\hline Redox & $\mathrm{mV}$ & $-284.50 \pm 4.95$ & $-331.50 \pm 2.12$ & $-153.00 \pm 30.61$ & $20.00 \pm 5.66$ & $-179.55 \pm 7.78$ & $100.50 \pm 10.61$ & $-153.50 \pm 19.09$ \\
\hline Temperature & ${ }^{\circ} \mathrm{C}$ & $22.40 \pm 0.00$ & $22.75 \pm 0.07$ & $27.20 \pm 0.00$ & $19.85 \pm 0.07$ & $28.55 \pm 0.35$ & $23.10 \pm 0.14$ & $29.40 \pm 0.42$ \\
\hline Organic matter & $\%$ & $1.95 \pm 0.65$ & $2.04 \pm 0.50$ & $1.06 \pm 0.75$ & $2.09 \pm 0.35$ & $0.81 \pm 0.63$ & $2.41 \pm 0.61$ & $2.60 \pm 0.66$ \\
\hline Organic nitrogen & $\%$ & 0.04 & 0.11 & 0.05 & 0.07 & 0.04 & 0.06 & 0.05 \\
\hline Sand & $\%$ & 89.57 & 48.68 & 91.60 & 26.23 & 85.29 & 98.82 & 65.88 \\
\hline \multirow[t]{2}{*}{ Silt-Clay } & $\%$ & 0.07 & 5.90 & 0.09 & 0.99 & 0.60 & 0.52 & 2.30 \\
\hline & Units & HT & IT & JT & KT & LT & MT & NT \\
\hline Sal & psu & $34.80 \pm 0.0$ & $36.97 \pm 0.06$ & $29.20 \pm 0.0$ & $24.17 \pm 0.06$ & $28.63 \pm 0.06$ & $22.53 \pm 0.06$ & $26.50 \pm 0.0$ \\
\hline $\mathrm{pH}$ & & $7.54 \pm 0.11$ & $7.63 \pm 0.04$ & $7.50 \pm 0.10$ & $7.55 \pm 0.02$ & $7.56 \pm 0.08$ & $7.65 \pm 0.03$ & $7.76 \pm 0.08$ \\
\hline$\left[\mathrm{O}_{2}\right]$ & $\mathrm{mg} / \mathrm{l}$ & $4.15 \pm 0.61$ & $0.39 \pm 0.02$ & $2.03 \pm 0.22$ & $0.53 \pm 0.09$ & $1.78 \pm 0.22$ & $0.28 \pm 0.02$ & $7.42 \pm 0.36$ \\
\hline Redox & $\mathrm{mV}$ & $-59.00 \pm 1.41$ & $-241.50 \pm 23.33$ & $62.00 \pm 8.49$ & $-228.50 \pm 3.54$ & $-75.00 \pm 93.34$ & $-158.00 \pm 2.83$ & $91.50 \pm 6.36$ \\
\hline Temperature & ${ }^{\circ} \mathrm{C}$ & $23.65 \pm 0.21$ & $26.45 \pm 0.64$ & $25.80 \pm 0.28$ & $26.30 \pm 0.00$ & $29.50 \pm 0.00$ & $25.95 \pm 0.07$ & $29.50 \pm 0.14$ \\
\hline Organic matter & $\%$ & $2.36 \pm 0.2$ & $2.28 \pm 0.74$ & $1.87 \pm 0.12$ & $2.78 \pm 0.61$ & $1.80 \pm 0.34$ & $2.32 \pm 0.46$ & $1.80 \pm 0.54$ \\
\hline Organic nitrogen & $\%$ & 0.24 & 0.07 & 0.04 & 0.05 & 0.05 & 0.06 & 0.23 \\
\hline Sand & $\%$ & 60.70 & 81.42 & 55.65 & 98.87 & 76.99 & 43.25 & 66.58 \\
\hline Silt-Clay & $\%$ & 10.32 & 4.82 & 1.02 & 0.71 & 5.56 & 1.15 & 2.77 \\
\hline
\end{tabular}

variables identified as significant by forward selection (Borcard et al. 2011; Oksanen 2011). The full model was tested for significance prior to looking for a parsimonious model. This procedure prevented inflation of the overall type I error (Blanchet et al. 2008). The free statistical software R (R Development Core Team 2009) was used for computations.

The following a priori null hypotheses were considered (1) there is no difference in the composition of the macrobenthic assemblages between sites and (2) there is no correlation between the environmental factors and the composition of the assemblages. Under these hypotheses, the composition of the assemblages would be uniform at any location of the estuary.

\section{RESULTS}

Salinity varied from $20.37 \pm 0.06$ (site BT) to marine values $36.97 \pm 0.06$ (site IT, Table 1 ). The $\mathrm{pH}$ was similar at all sites (close to neutral), while other parameters, such as redox potential and oxygen concentration, organic nitrogen and silt-clay content, varied widely. Organic matter content was low, never higher than $3 \%$. Grain size was mainly characterized by medium and coarse sand. Temperature was relatively high because of the summer heating of the sediment, which in turn depended on the time of low tide at which temperature was measured. The cluster analysis applied to the abiotic data set displayed on the PCA ordination of these variables identified three groups of sites (Fig. 2). The groups of sites were separated in relation to the first axis mainly in accordance with the level of oxygen concentration and redox potential (Table 1), while the second axis seemed more related to sediment grain size.

A total of 2961 individuals belonging to 21 taxa were counted and identified (Table 2). The gastropod Hydrobia ulvae (Pennant, 1777) was the most abundant species, being quite widespread within the estuary. The

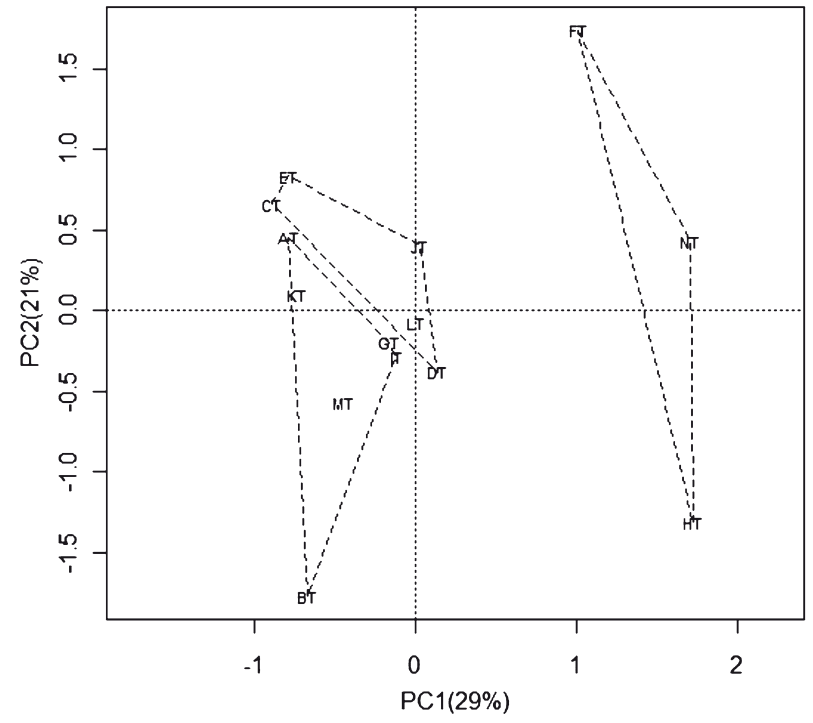

FIG. 2. - Ordination by principal components analysis of the sampling sites as a function of the abiotic variables (Table 1, except temperature). The variance explained by the first two axes is provided.

polychaete Hediste diversicolor (O.F. Müller, 1776) and the bivalve Scrobicularia plana (da Costa, 1778) were the second and the third most abundant species, respectively. The most abundant isopod was Cyathura carinata (Krøyer, 1847), which was also widely distributed within the estuary. The distribution of the bivalve Mya arenaria is described for the first time along the estuary (Table 2); the species was recently recorded for the first time in the Tagus estuary (Conde et al. 2010). Polychaetes (7 species) and bivalves ( 5 species) were the most diverse taxa. Deposit feeders were the most common feeding guild, followed in decreasing order of occurrence by filter feeders and carnivorous species (Table 2).

Ordination of the sites by NMDS in relation to the GAM contours of salinity showed a salinity gradi- 


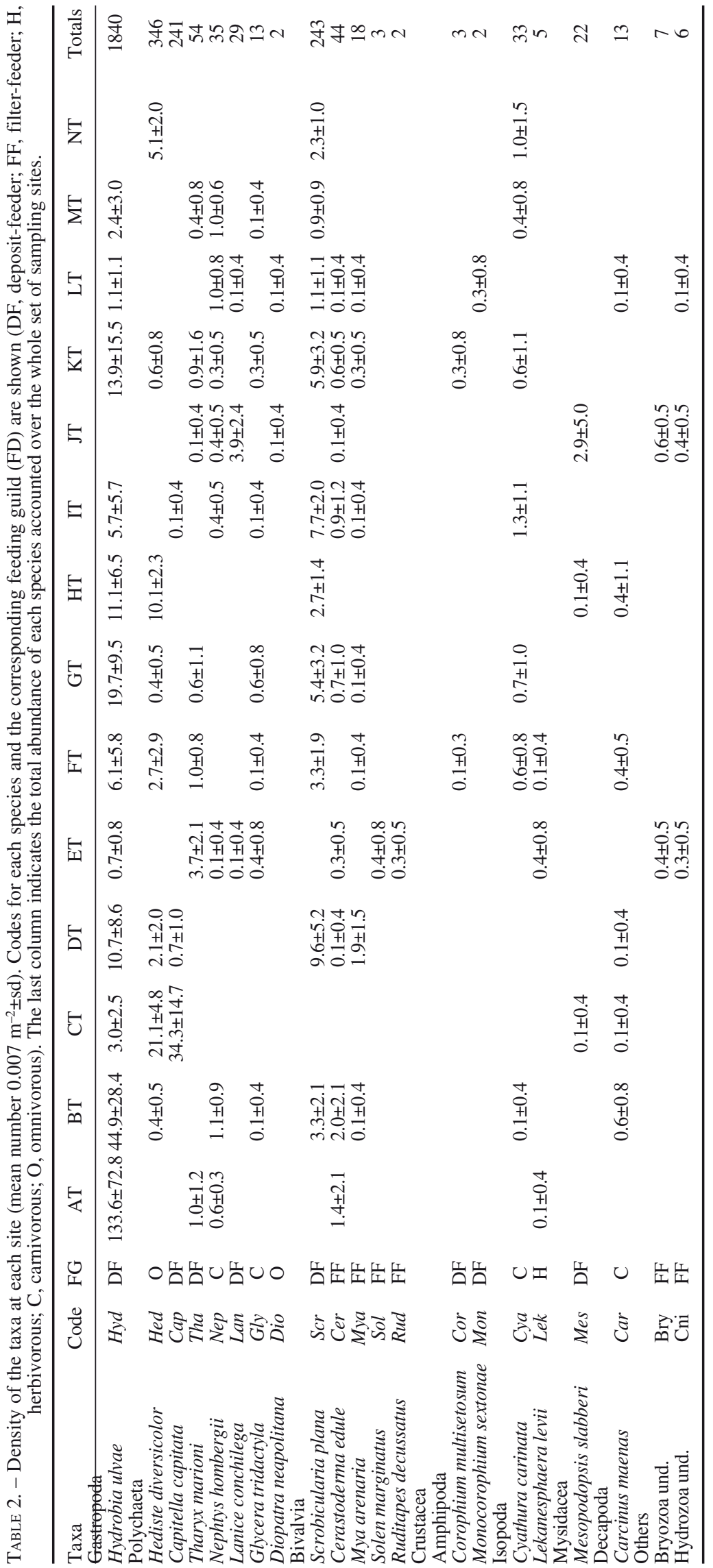

ent (Fig. 3a). The superimposed vector of salinity almost perpendicular to the GAM contours indicates the direction of the maximum rate of change (Oksanen 2011). However, the observed salinity gradient was not a significant environmental factor to explain the distribution of the macrobenthic assemblages $\left(\mathrm{r}^{2}=0.08, \mathrm{p}=0.658\right)$. A cluster analysis identified three groups of sites (Fig. $3 \mathrm{~b}$ ), displayed in the ordination with a satisfactory goodness of fit (stress $=0.11$; Clarke and Warwick 1994).

The RDA parsimonious model obtained by forward selection is shown in Figure 4 . The significant environmental variables that provided the best fit to the model (AIC $=-13.9 ; \mathrm{R}^{2}$ adj $=0.39 ; F$ ratio $=3.74 ; \mathrm{p}<0.001)$ were organic matter content, oxygen concentration and redox potential. The global permutation test applied to the parsimonious model only proceeded because the global permutation test applied to the full model was significant $(F$-ratio $=1.65 ; \mathrm{p}=0.046)$. The permutation test applied to each constraint variable of the parsimonious model yielded the results shown in Table 3. The first canonical axis alone explained $17.4 \%$ of the variance, and the second axis $15.3 \%$ (equal to 32.7 $\%$ of variance explained by the first two canonical axes). The third canonical axis only accounted for $6.3 \%$ of the variance. The species-environment correlations were 0.90 and 0.86 for the first and the second constraint axes, respectively.

The three groups of sites formed by cluster analysis already shown in Figure $3 \mathrm{~b}$ are also recognizable in Figure 4b. However, because the RDA plot was based on the correlation matrix, the degree of correlation between sites within the same cluster is very variable. Nonetheless, the transition between the groups of assemblages is visualized as a type of "continuum". In any case, the three clusters of sites can be recognized in relation to the environmental variables found significant by the parsimonious model (Fig. 4a) and by the species correlated with those groups (Fig. 4b). The organic matter content was more closely related to the first canonical axis, while oxygen and redox potential were related to the second axis. Therefore, the sites on the left side of the plot were associated with higher values of organic matter. In turn, the sites on the lower part of the 
TABLE 3. - Summary of the results to assess the significance of the environmental variables and the canonical axes included in the parsimonious RDA model, constructed with the data presented in Table 1 and 2 (except temperature). Oxy, oxygen; OM, organic matter.

\begin{tabular}{lcccccc}
\hline Test on & Source & Df & Var & F & N. Perm & p \\
\hline a)Terms & Oxy & 1 & 0.098 & 4.24 & 1999 & $<0.001$ \\
& OM & 1 & 0.081 & 3.64 & 1999 & 0.004 \\
& Redox & 1 & 0.071 & 3.33 & 1999 & 0.002 \\
& Residual & 10 & 0.225 & & & \\
b) Axes & RDA1 & 1 & 0.117 & 5.00 & 199 & $<0.001$ \\
& RDA2 & 1 & 0.106 & 4.39 & 199 & 0.003 \\
& RDA3 & 1 & 0.044 & 1.81 & 99 & 0.066 \\
& Residual & 10 & 0.225 & & & \\
\hline
\end{tabular}

plot were related to lower values of oxygen and redox potential, showing the opposite trend to those sites included in the upper part of the ordination. Therefore, the association of sites ET-JT may be differentiated from the other clusters of sites, mainly by the low organic matter content in the sediment and also by lower values of oxygen and redox potential. The polychaete Lanice conchilega (Pallas, 1766) was related to ET-JT sampling sites (Fig. 4b). The group of sites in the third quadrant of the ordination, characterized by the gastropod Hydrobia ulvae (Fig. 4b), were also associated with lower values of oxygen and redox potential at the opposite end of the gradient in relation to the cluster of sites in the fourth quadrant, characterized by the polychaete Hediste diversicolor. The third and fourth quadrant of the ordination comprised sites with higher organic matter content. The IndVal index (minimum value of 0.56 for Hydrobia ulvae) revealed that the latter three species were significant in relation to the three cluster of sites described ( $\mathrm{p}_{\mathrm{adj}}<0.05$ ), in addition to the Bryozoans and Hydrozoans also characteristic of the ET-JT group of sites. The three clusters of sites iden-

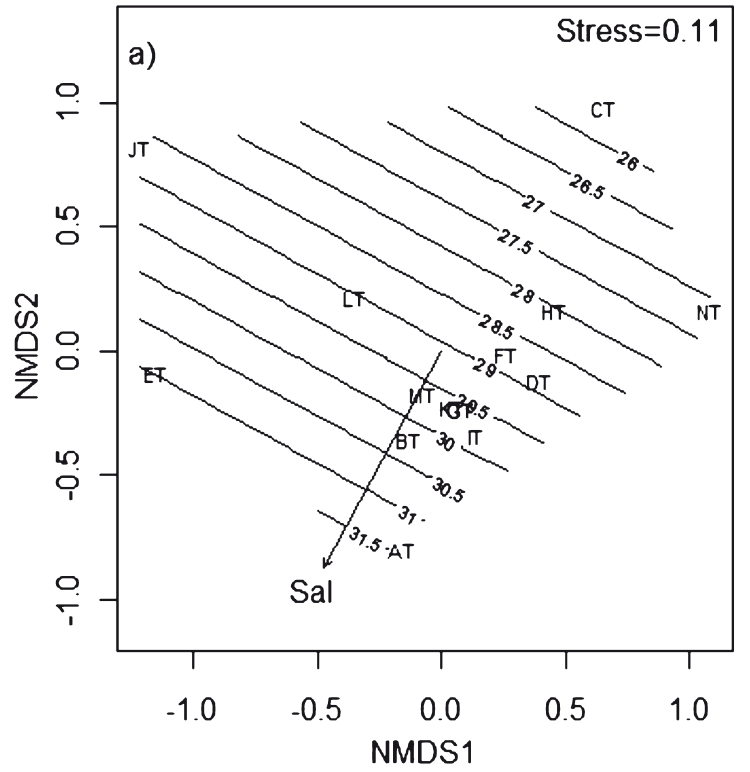

tified by cluster analysis and coherently displayed in the ordinations (Fig 3b, 4b) are designated hereafter as outer (ET-JT), intermediate (AT-BT-GT-IT-KT-LTMT) and inner (CT-DT-FT-HT-NT) groups.

Analysis of the composition of the assemblages using PERMANOVA, over 4900 permutations, found significant differences between sites (global test, $\mathrm{F}_{13,84}=12.87$, $\mathrm{p}=0.0002$ ). Post-hoc comparisons between sites showed significant differences in the composition of the assemblages in most cases $(p<0.0365)$. However, sampling sites FT and DT that belong to the same cluster (Figs. 3b and $4 \mathrm{~b}$ ) were similar in composition to site KT included in a different cluster of sites ( $p>0.05$ in both cases). This result suggests that species observed in the three latter sites such as Hydrobia ulvae, Hediste diversicolor and Scrobicularia plana (Table 2) are linking species between progressively different assemblages or habitat groups within the estuary.

The values of the primary parameters and derived indices were grouped and sequentially displayed in accordance with the inner, intermediate and outer groups (Fig. 5). Additionally the Kruskal-Wallis test was applied to the values of the ecological parameters between groups of sites that were compared when significant differences were found (Table 4). Abundance was lower in the outer group in comparison with both the inner and intermediate group. The last mentioned group had great variability in abundance, mainly due to the non-homogenous distribution of the gastropod $\mathrm{Hy}$ drobia ulvae between samples at sites AT, BT, GT and $\mathrm{KT}$. Species richness tended to be slightly higher in the intermediate group but not enough to be declared significantly different (Table 4). Diversity showed higher variability at the intermediate and outer groups of sites and it was not found significant despite the lowest value in sampling site AT. Evenness was found different

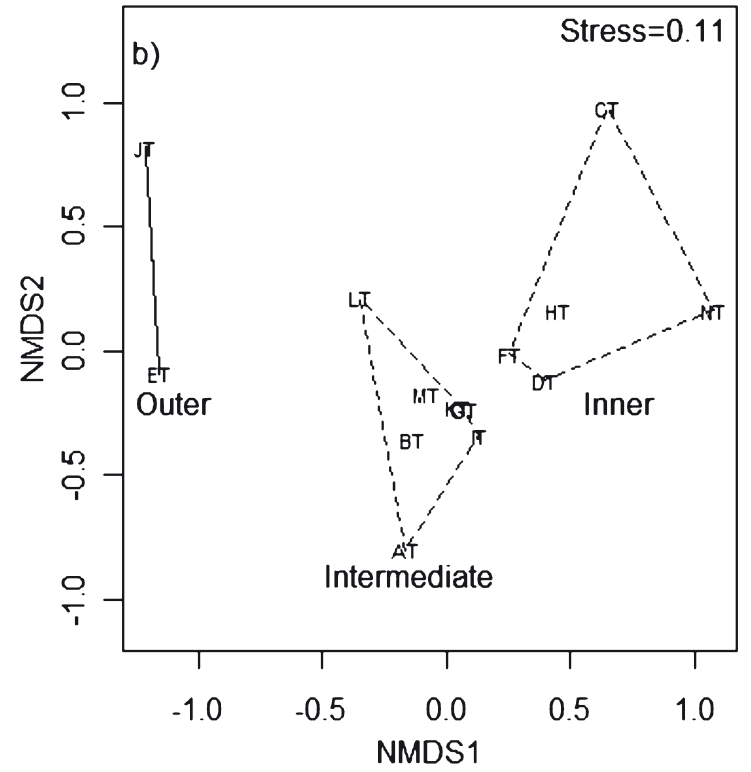

FIG. 3. - NMDS plots: a) shows the ordination of the sampling sites, the GAM fitting contours for salinity and the fitted vector gradient (Sal), and b) shows the same ordination of the sites and the groups identified by cluster analysis: outer, intermediate and inner. 

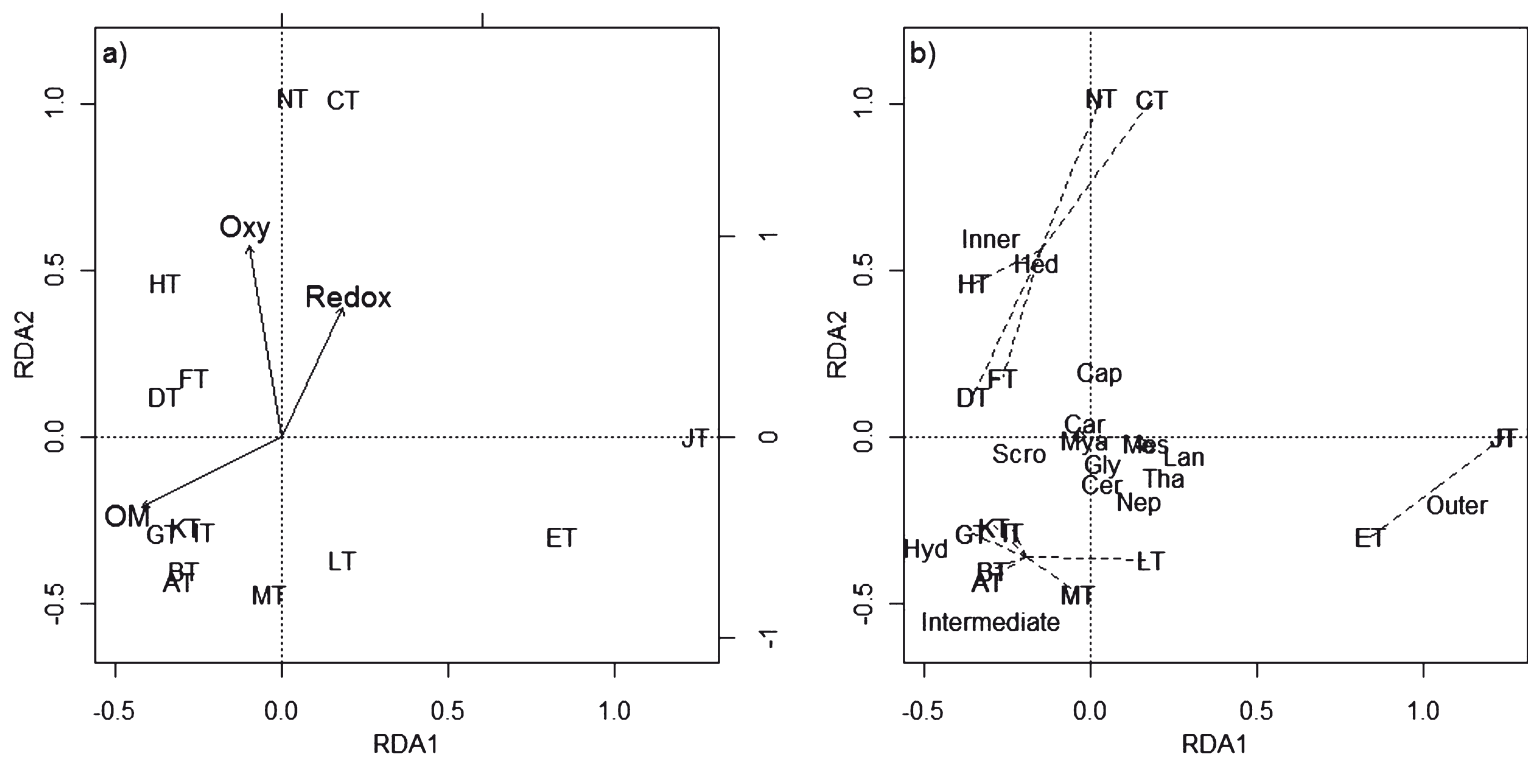

FIG. 4. - Triplot graphs of the RDA parsimonious model: a) shows the environmental variables in relation to the considered sites, and b) shows the groups of sites identified by cluster analysis (outer, intermediate and inner) and the characteristic species. For species codes see Table 2.
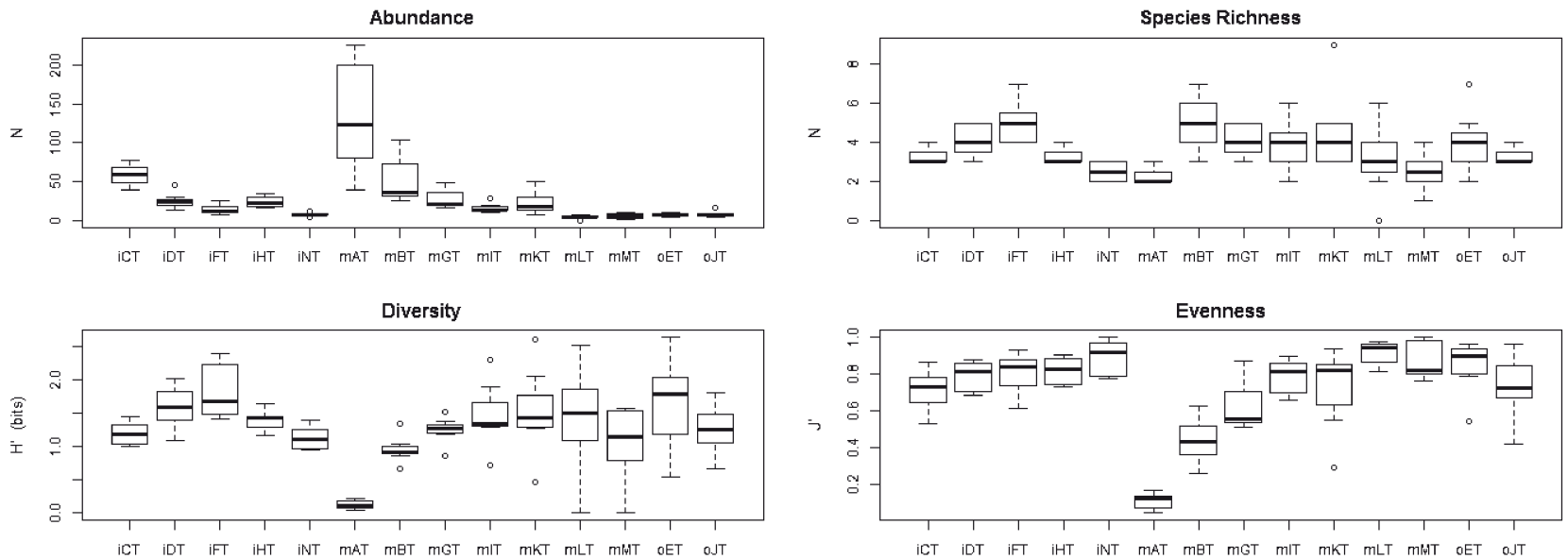

FIG. 5. - Box plot of the primary parameters and derived indices grouped by clusters of sites. The first lower-case letter for the sampling sites on the x-axis identifies the clusters of sites: inner (i), intermediate $(\mathrm{m})$ and outer $(\mathrm{o})$. The horizontal line within each box of any plot shows the median, the bottom and tops of the box show the $25^{\text {th }}$ and $75^{\text {th }}$ percentiles, respectively. The vertical dashed lines show either the maximum and minimum value or 1.5 times the interquartile range. Individual points are outliers.

TABLE 4. - Summary of the Kruskall-Wallis test (K-W) and pos-hoc pairwise comparison testing the significance of the primary parameters between clusters of sites (In, Inner; It, Intermediate; Ot, Outer). The mean ( \pm sd) of each parameter is also provided. Df, degrees of freedom; $\mathrm{p}$, probability; significance $\mathrm{p}<0.001^{* * *}, \mathrm{p}<0.01^{* *}, \mathrm{p}<0.05^{*}$; ns, not significant.

\begin{tabular}{lccccccc}
\hline $\begin{array}{l}\text { Ecological } \\
\text { parameter }\end{array}$ & In & $\begin{array}{c}\text { Mean } \pm \text { sd } \\
\text { It }\end{array}$ & Ot & Chi-squared & $\begin{array}{c}\text { K-W } \\
\text { Df }\end{array}$ & p & Post-hoc comparison \\
\hline Abundance & $26.3 \pm 19.6$ & $39.8 \pm 52.6$ & $7.9 \pm 3.0$ & 15.7652 & 2 & $<0.001$ & $\mathrm{In}^{2}>\mathrm{Ot}^{* * *}$ and It $>\mathrm{Ot}^{* * *}$ \\
Species Richness & $3.6 \pm 1.1$ & $3.8 \pm 1.5$ & $3.6 \pm 1.3$ & 0.0299 & 2 & 0.980 & $\mathrm{~ns}$ \\
Diversity & $1.4 \pm 0.3$ & $1.2 \pm 0.6$ & $1.4 \pm 0.6$ & 4.5747 & 2 & 0.101 & $\mathrm{~ns}$ \\
Evenness & $0.8 \pm 0.1$ & $0.6 \pm 0.3$ & $0.8 \pm 0.2$ & 5.754 & 2 & 0.056 & $\mathrm{In}>\mathrm{It}{ }^{*}$ \\
\hline
\end{tabular}

between groups due to the significantly higher values in the inner group than in the intermediate group, the latter largely influenced by the high numbers of the gastropod Hydrobia ulvae.

Biomass, expressed as blotted wet weight, was significantly different between groups of sites
(Kruskal-Wallis test, $\chi^{2}=39.18, \mathrm{df}=2, \mathrm{p}<0.001$; Fig. $6)$. Wet weight was significantly lower in the outer

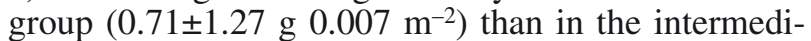
ate (Wilcoxon's test, $\mathrm{W}=537, \mathrm{p}<0.001$ ) and the inner groups (Wilcoxon's test, $\mathrm{W}=409, \mathrm{p}<0.001$ ). The latter two groups had a non-significantly different wet 

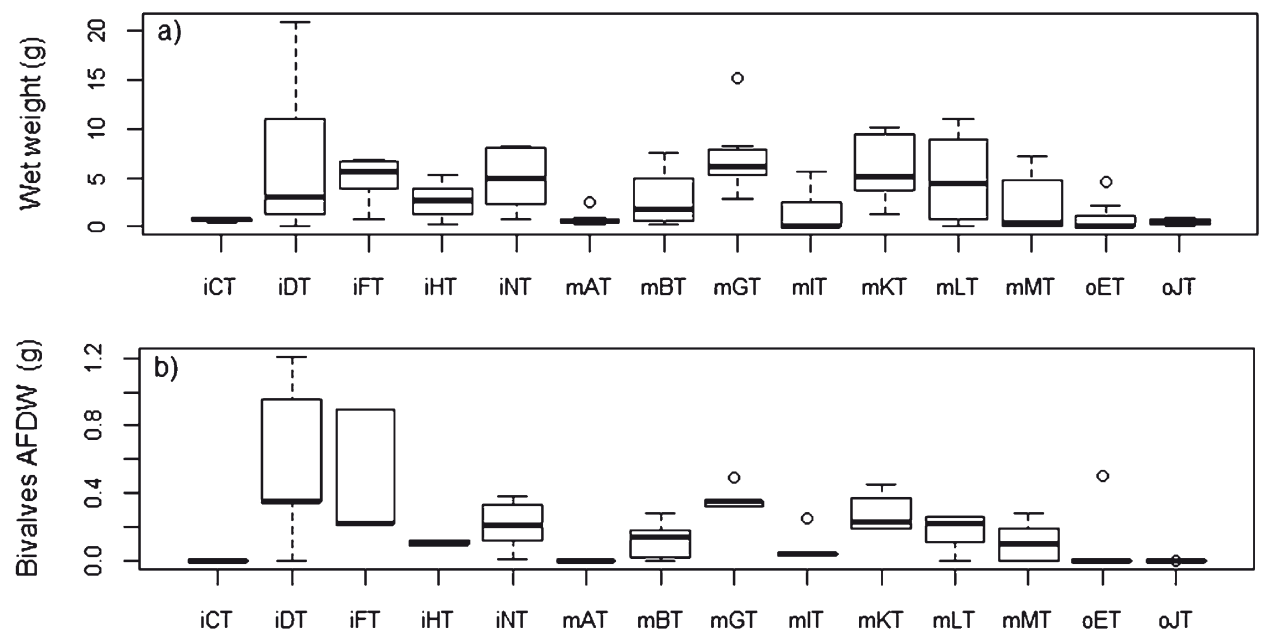

FIG. 6. - Boxplot of the biomass, a) shown as wet weight for all species at each site, and b) shown as AFDW for bivalves at each site. The horizontal line within each box shows the median and the bottom and tops of the box show the $25^{\text {th }}$ and $75^{\text {th }}$ percentiles, respectively. The vertical dashed lines show either the maximum and minimum value or 1.5 times the interquartile range. Individual points are outliers.

weight with mean values of $3.72 \pm 3.81 \mathrm{~g} 0.007 \mathrm{~m}^{-2}$ and $3.99 \pm 4.33 \mathrm{~g} 0.007 \mathrm{~m}^{-2}$, respectively. As a general trend, values were higher at sampling sites where adult bivalves occurred. Accordingly, from a total fresh weight biomass of $297.5 \mathrm{~g}, 88.8 \%$ corresponded to four bivalves: Scrobicularia plana (61.8\%), Mya arenaria (21.8\%), Cerastoderma edule (Linnaeus, 1758) (3.1\%) and Solen marginatus Pulteney, 1799 (2.1\%). The polychaete Hediste diversicolor was the fourth contributor to total biomass, accounting for 2.3\%; the polychaetes Nephtys hombergii Savigny in Lamarck, 1818 (1.2\%) and Lanice conchilega (1\% of total wet weight) were also important contributors. Two species also accounted for more than $1 \%$ of wet weight: the gastropod Hydrobia ulvae (1.6\%) and the decapod Carcinus maenas (Linnaeus, 1758) (1.6\%). Total wet weight (Fig. 6a) and AFDW of bivalves (Fig. 6b) were highly correlated (Spearman rank correlation, $\rho=0.80$, $\mathrm{p}<0.001$ ), a finding that was mainly attributable to Scrobicularia plana except at sites DT and ET, where Mya arenaria and Solen marginatus respectively predominated in terms of biomass.

\section{DISCUSSION}

The present study shows the importance of the lateral gradient in explaining the distribution of macrobenthic assemblages in the Tagus estuary. The recognition of a lateral gradient that influenced the composition of the assemblages was also distinguished by Moreira et al. (1993) in the Ria of Aveiro, northern Portugal. Similarly, the lateral gradient may be recognized in other studies conducted in smaller areas of the Tagus estuary, such as Rodrigues et al. (2006) in a study site near Alcochete, Silva et al. (2006) in the northern bank of the estuary, and Salgado et al. (2007) in an area close to the NT sampling station. The lateral gradient is synonymous with the cross-sectioned spatial gradi- ent pointed out by McLusky (1993). Hydrodynamics may condition both the sediment and the bottom water characteristics, thus helping to explain the structure and distribution of the assemblages (Mucha and Costa 1999, Rodrigues et al. 2011). Geophysics studies in estuaries explicitly mention the lateral gradient in relation to changes in bathymetry, current velocities and sediment transport (Lacy et al. 2003, Ralston and Geyer 2009). Therefore, the hydrodynamic regime (a dynamic factor) established between tidal cycles in intertidal regions may condition the macrobenthic assemblage composition in addition or complementary to the static sediment characteristics such as those used in this study. The spatial variation in the values of organic matter content, oxygen and redox potential were recognized as components of the lateral gradient in this study. Although oxygen was more significant than organic matter content, the latter environmental variable was more closely correlated with the first RDA axis (smaller angle), which explained most of the model variance (Table 3, Fig. 4). Silva et al. (2006) and Salgado et al. (2007) also found that the organic matter content of the sediment was an important variable explaining the differences in the composition of assemblages in the Tagus estuary. Moreover, Silva et al. (2006) also identified that the type of sediment is an important factor in structuring the intertidal macroinvertebrate communities, which are in turn influenced by the level of precipitation. Rodrigues et al. (2006) reported a relationship between organic matter content (negatively correlated with redox potential), sediment grain size and the groups of assemblages. Oxygen and redox potential were not identified as important environmental variables in previous studies in the Tagus estuary (Silva et al. 2006, Salgado et al. 2007, França et al. 2009) although oxygen and/or redox potential may be considered as important factors determining the structure of estuarine assemblages (Borja et al. 2006, Rodrigues et al. 2011). 
The use of ordination techniques allowed to recognize three groups of sites in this study. (Figs. $3 \mathrm{~b}$ and $4 \mathrm{~b}$ ). Interestingly, the groups of sites inner, intermediate and outer, corresponded to their geographical positions (Fig. 1). In general, the outer group was close to the main channel entrance of the estuary (ET-JT), the inner group comprised sites in confined locations and the remaining group belonged to sites (except AT) located at intermediate positions. Therefore, the geographical location is among the factors conditioning the composition of the macrobenthic assemblages.

The species of these three groups of assemblages have been reported as characteristic of the Tagus estuary in several studies (Rodrigues et al. 2006, Silva et al. 2006, França et al. 2009). The distribution of the assemblages and key species described by Calvário (2001) in the Tagus estuary are similar to the findings of this study: Lanice conchilega in the polyhaline sector and the association Hediste diversicolor-Scrobicularia plana-Cyathura carinata characterizing the intertidal zone where salinity ranges between 25 and 5. Moreover, Calvário $(1982,2001)$ explicitly states the existence of a transition between communities in the Tagus estuary. Indeed, the different groups of assemblages identified in the present study seemed to follow a particular pattern of spatial succession and a transitional distribution from an outer environment influenced by marine conditions to the inner sheltered parts of the estuary. A transition between communities, or a series rather than a zonation (sensu Ysebaert et al. 2003), has also been described in other marine systems in the northern Iberian Peninsula (Viéitez 1976, Junoy and Viéitez 1990, Borja et al. 2006), in agreement with the findings of this study. The distribution of the feeding guilds was also associated with the transition between assemblages in the estuary. This seems to be a general pattern in estuaries: filter feeders and carnivorous species dominate at the outer and intermediate sites near the estuary mouth, while deposit feeders and omnivores predominate at inner habitats, a distribution previously observed by other authors (Ysebaert et al. 1998, García-Arberas and Rallo 2002, Gaudêncio and Cabral 2007).

A salinity gradient was recognizable at the study site (Fig 3a), as would be expected in an estuary (Elliot and McLusky 2002). However, it was not found to be a major environmental factor in structuring the macroinvertebrate assemblages within the study site. Therefore, salinity is not considered as a stressful environmental factor that inhibited the occurrence of some species (Barnes 1989, Attrill and Rundle 2002) in the present study, so the role of the lateral gradient is reinforced. Thus, salinity is only identified as a key environmental factor in structuring the estuarine community when a significant salinity range is captured (Calvário 1982, Gaudêncio and Cabral 2007). Ysebaert et al. (2003) stated that the role of environmental variables may be masked by the scale at which studies are performed, as well as by the type of estuary under study. The large size of the Tagus estuary (area $c a .325 \mathrm{~km}^{2}$ ) may be the main reason that masked the non-significant effect of salinity in a number of studies conducted on a medium/small scale in this estuary. Conversely, salinity was found to be a major factor determining the structure of the estuarine community in other Portuguese estuarine systems when enough large areas were sampled and changes in salinity matched the distribution of different macrobenthic assemblages (Moreira et al. 1993, Sousa et al. 2006, 2008, Rodrigues et al. 2011).

The high values of evenness indicated a suitable balance between species in the assemblages. The AT site displayed low values of species richness, diversity and evenness as well as high values of abundance, suggesting the existence of a disturbance event. Site AT was expected to belong to the cluster of sites ETJT (Figs. 3b and 4b) because of its location (Fig. 1). One possible explanation for this unexpected result may be the proximity of the AT site to a passenger boat waterway that continuously links Lisbon to the towns of Seixal and Barreiro. Persistent boat-wash may negatively affect the macrobenthic fauna, an issue not frequently addressed in the literature. However he possibility that chemical pollution by heavy metals in this estuarine area, especially by cadmium and lead (Vale et al.2008), may limited the inhabitability of this sampling site cannot be ruled out.

The present study stresses the role of the lateral gradient in controlling the distribution of estuarine macrofaunal assemblages. The large dimension of the Tagus estuary appears to favour different habitat types at different intertidal locations, thus helping to structure the macrobenthic assemblages in relation to changing environmental factors, among which salinity is not included. The present data jointly with the study, for instance, of Carvalho et al. (2005) may allow us to consider estuaries from another perspective. The latter authors found similar habitat types and feeding guild distribution in the Óbidos lagoon, $100 \mathrm{~km}$ north of the Tagus estuary. These authors distinguished three main areas of the lagoon in relation to current dynamics: an outer, an intermediate and an inner area, none of them attributable to a salinity gradient. Therefore, significant areas of estuaries may resemble other marine coastal ecosystems ecologically when the lateral gradient is dominant over the salinity gradient.

\section{ACKNOWLEDGEMENTS}

This study was funded by the Lisbon Port Authority (APL). We thank Commander Eduardo dos Santos and Engineer Susana Rolo from the APL. We also thank Dinamene Sousa for field and lab assistance. We are grateful to the Portuguese Air Force for granting access to military restricted areas. The first author was also funded (SFRH / BD / 48928 / 2008) by the Portuguese Foundation for Science and Technology. 


\section{REFERENCES}

Anderson M.J. 2001. A new method for non-parametric multivariate analysis of variance. Austral Ecol. 26: 32-46.

Anderson M.J. 2005. PERMANOVA: a FORTRAN computer program for permutational multivariate analysis of variance. Depart. Stat., Univ. Auckland, New Zealand, 24 pp.

Attrill M.J., Rundle S.D. 2002. Ecotone or ecocline: ecological boundaries in estuaries. Estuar. Coast. Shelf Sci. 55: 929-936.

Barnes R.S.K. 1989. What, if any, is a brackish water fauna? Trans. Roy. Soc. Edinburgh, Earth Sci. 80: 235-240.

Blanchet F.G., Legendre P., Borcard D. 2008. Forward selection of explanatory variables. Ecology 89: 2623-2632.

Bocher P., Piersma T., Dekinga A., Kraan C., Yates M.G., Guyot T., Folmer E.O., Radenac G. 2007. Site and species-specific distribution patterns of molluscs at five intertidal soft sediment areas in northwest Europe during a single winter. Mar. Biol. 151: 577-594.

Borcard D., Gillet F., Legendre P. 2011. Numerical ecology with R. Springer, New York, 306 pp

Borja A., Muxika I., Franco J. 2006. Long-term soft-bottom benthos recovery, following urban and industrial sewage treatment in the Nervión estuary (southern Bay of Biscay). Mar. Ecol. Prog. Ser. 313: 43-55.

Calvário J. 1982. Estudo ambiental do estuário do Tejo: povoamentos bentónicos intertidais (substratos móveis). CNA TEJO 19, Rel 18, Comissão Nacional do Ambiente, Lisboa, Portugal.

Calvário J. 2001. Characterization of the Tagus estuary macrobenthic communities. Bol. Mus. Mun. Funchal 6: 313-330.

Carvalho S., Moura A., Gaspar M.B., Pereira P., Cancela da Fonseca L., Falcão M., Drago T., Leitão F., Regala J. 2005. Spatial and inter-annual variability of the macrobenthic communities within a coastal lagoon (Óbidos lagoon) and its relationship with environmental parameters. Acta Oecol. 27: 143-159.

Clarke K.R., Warwick R.M. 1994. Change in marine communities: an approach to statistical analysis and interpretation. Plymouth Marine Laboratory, Plymouth, 144 pp.

Conde A., Novais J., Domínguez J. 2010. Southern limit of distribution of the soft-shell clam Mya arenaria on the Atlantic East Coast. Biol. Invasions 12: 429-432.

Crawley, M.J. 2007. The R book. Wiley, Chichester, 942 pp.

Dufrêne M., Legendre P. 1997. Species assemblages and indicator species: the need for a flexible asymmetrical approach. Ecol. Monogr. 67: 345-366.

Elliott M., McLusky D.S. 2002. The need for definitions in understanding estuaries. Estuar. Coast. Shelf Sci. 55: 815-827.

França S., Vinagre C., Pardal M.A., Cabral H.N. 2009. Spatial and temporal patterns of benthic invertebrates in the Tagus estuary, Portugal: comparison between subtidal and an intertidal mudflat. Sci. Mar. 73: 307-318.

Gamito S., Chainho P., Costa J.L., Medeiros J.P., Costa M.J., Marques, J.C. 2010. Modelling the effects of extreme events on the dynamics of the amphipod Corophium orientale. Ecol. Model. 221: 459-466.

García-Arberas L., Rallo A. 2002. The intertidal soft-bottom infaunal macrobenthos in three Basque estuaries (Gulf of Biscay): a feeding guild approach. Hydrobiologia 475/476: 457-468.

Gaudêncio M.J., Cabral H.N. 2007. Trophic structure of macrobenthos in the Tagus estuary and adjacent coastal shelf. Hydrobiologia 587: 241-251.

Jansen J.M., Pronker A.E., Bonga S.W., Hummel H. 2007. Macoma balthica in Spain, a few decades back in climate history. J. Exp. Mar. Biol. Ecol. 344: 161-169.

Junoy J., Viéitez J.M. 1990. Macrozoobenthic community structure in the Ria de Foz, an intertidal estuary (Galicia, Northwest Spain). Mar. Biol. 107: 329-339.

Lacy J.R., Stacey M.T., Burau J.R., Monismith S.G. 2003. Interaction of lateral baroclinic forcing and turbulence in an estuary. $J$. Geophys. Res. 108.

Legendre P., Gallagher E.D. 2001. Ecologically meaningful transformations for ordination of species data. Oecologia 129: 271-280.

Legendre P., Legendre L. 1998. Numerical ecology. Elsevier, Amsterdam, $853 \mathrm{pp}$

Little C. 2000. The Biology of Soft Shores and Estuaries. Oxford Univ. Press, Oxford, 252 pp.

McLusky D.S. 1993. Marine and Estuarine Grandients - an over- view. Neth. J Aquat. Ecol. 27: 489-493.

McLusky D.S., Elliott M. 2004. The Estuarine Ecosystem: ecology, threats and management. Oxford Univ. Press Inc., New York, 216 pp.

Moreira M.H., Queiroga H., Machado M.M., Cunha M.R. 1993. Environmental gradients in a southern Europe estuarine system: Ria de Aveiro, Portugal. Implications for soft bottom macrofauna colonization. Neth. J. Aquat. Ecol. 27: 465-482.

Mucha A.P., Costa M.H. 1999. Macrozoobenthic community structure in two Portuguese estuaries: Relationship with organic enrichment and nutrient gradients. Acta Oecol. 20: 363-376.

Nixon S.W. 1988. Physical energy inputs and the comparative ecology of lake and marine ecosystems. Limnol. Oceanogr. 33: 1005-1025.

Oksanen J. 2011. Multivariate Analysis of Ecological Communities in R: VEGAN Tutorial, http://cc.oulu.fi/ jarioksa/opetus/ metodi/vegantutor.pdf.

Oksanen J., Kindt R., Legendre P., O'Hara R.B. 2006. VEGAN: Community Ecology Package Version 1.8-2. URL: http:// cran.r-project.org.

Pielou, E.C. 1969. An introduction to mathematical ecology. Wiley \& Sons, New York, 286 pp.

Queiroga H. 1990. Corophium multisetosum (Amphipoda: Corophiidae) in Canal de Mira, Portugal: some factors that affect its distribution. Mar. Biol. 104: 397-402.

R Development Core Team. 2009. R: a Language and Environment for Statistical Computing. R Foundation for Statistical Computing. Available from: http://www.R-project.org.

Ralston D.K., Geyer W.R. 2009. Episodic and long-term sediment transport capacity in The Hudson River estuary. Estuar. Coast 32: 1130-1151.

Rodrigues A.M., Meireles S., Pereira T., Gama A., Quintino V. 2006. Spatial Patterns of Benthic Macroinvertebrates in Intertidal Areas of a Southern European Estuary: The Tagus, Portugal. Hydrobiologia 555: 99-113.

Rodrigues A.M., Quintino V., Sampaio L., Freitas R., Neves R. 2011. Benthic biodiversity patterns in Ria de Aveiro, Western Portugal: Environmental biological relationships. Estuar. Coast. Shelf Sci. 95: 338-348.

Salgado J.P., Cabral H.N., Costa M.J. 2007. Spatial and temporal distribution patterns of the macrozoobenthos assemblage in the salt marshes of Tejo estuary (Portugal). Hydrobiologia 587: 225-239.

Silva G., Costa J.L., Raposo de Almeida P., Costa M.J. 2006. Structure and dynamics of a benthic invertebrate community in an intertidal area of the Tagus estuary, Western Portugal: a six year data series. Hydrobiologia 555: 115-128.

Shannon C., Weaver W. 1963. The mathematical theory of communication. Urbana Univ. Press, Illinois, $127 \mathrm{pp}$

Sousa R., Dias S., Antunes C. 2006. Spatial subtidal macrobenthic distribution in relation to abiotic conditions in the Lima Estuary, NW of Portugal. Hydrobiologia 559: 135-148.

Sousa R., Dias S., Freitas V., Antunes C. 2008. Subtidal macrozoobenthic assemblages along the River Minho estuarine gradient (NW of Iberian Peninsula). Aquat. Conserv.: Mar. Freshw. Ecosyst. 18: 1063-1077.

Vale C., Canário J., Caetano M., Lavrado J., Brito P. 2008. Estimation of the anthropogenic fraction of elements in surface sediments of the Tagus Estuary (Portugal). Mar. Pollut. Bull. 56: 1353-1376.

Viéitez J.M. 1976. Ecología de Poliquetos y Moluscos de la playa de Meira (Ría de Vigo). Inv. Pesq. 40: 223-248.

Warwick R.M., Goss-Custard J.D., Kirby R., George C.L., Pope N.D., Rowden A.A. 1991. Static and dynamic environmental factors determining the community structure of estuarine macrobenthos in SW Britain: why is the Severn estuary different? $J$. Appl. Ecol. 28: 1004-1026.

Ysebaert T., Herman P.M.J., Meire P., Craeymeersch J., Verbeek H., Heip C.H.R. 2003. Large-scale spatial patterns in estuaries: estuarine macrobenthic communities in the Schelde estuary, NW Europe. Estuar. Coast. Shelf Sci. 57: 335-355.

Ysebaert T., Meire P., Coosen J., Essink K. 1998. Zonation of intertidal macrobenthos in the estuaries of Schelde and Ems. Aquat. Ecol. 32: 53-71.

Scient. ed.: M. Gaspar.

Received April 2, 2012. Accepted October 23, 2012.

Published online Janury 21, 2013. 